\title{
Handedness-Related Cortical Modulation of the Vestibular-Ocular Reflex
}

\author{
Qadeer Arshad,* Yuliya Nigmatullina, ${ }^{*}$ and Adolfo M. Bronstein \\ Academic Department of Neuro-Otology, Division of Brain Sciences, Imperial College London, London, W6 8RF, United Kingdom
}

\begin{abstract}
Multisensory visuo-vestibular cortical areas are important for spatial orientation and facilitate the control of the brainstem-mediated vestibular ocular reflex (VOR). Despite reports of visual input and cognitive tasks modulating the VOR through cortical control, it is unknown whether higher-order visual stimuli such as bistable perception and attention tasks involving visual imagery have an effect on the VOR. This is a possibility since such stimuli recruit cortical areas overlapping with those engaged during vestibular activation. Here we used a novel paradigm in which human subjects view bistable perceptual stimuli or perform complex attention tasks during concurrent vestibular stimulation. Bistable perceptual phenomena and attention tasks asymmetrically modulated the VOR but only if they involved a visuospatial component (e.g., binocular motion rivalry but not color rivalry). Strikingly, the lateralization effect was dependent upon the subjects' handedness, making this report the first behavioral demonstration that vestibular cortical processing is strongly lateralized to the non-dominant hemisphere. Furthermore, we show that perceptual transitions can modulate the dynamics of the vestibular system contingent upon the presence of a spatial component in the perceptual transition stimuli. Both perceptual transitions and attentional tasks are thought to invoke a redirection of spatial attention. We infer that such redirection of spatial attention engages multisensory vestibular cortical areas that modulate low-level vestibular function which, in turn, may contribute to spatial orientation.
\end{abstract}

\section{Introduction}

Visual and vestibular functions are complementary for gaze stabilization and maintenance of spatial orientation during head perturbations. Gaze stabilization is partly mediated by retinal slip velocity signals and the vestibular ocular reflex (VOR). Additional higher-order integration of visual and vestibular velocity signals is critical for conscious perception of body position in space and to modulate lower-brainstem vestibular reflexes such as the VOR (Suzuki et al., 2001).

In healthy adults, VOR responses are symmetrical for right and leftward rotations. The responses can be voluntarily modified bidirectionally by visual targets and non-visual tasks (e.g., VOR suppression occurs if subjects are asked to focus on real or imaginary targets rotating with them; Barr et al., 1976). Moreover, simple cognitive tasks such as mental arithmetic increase subjects' attentiveness and, as a result, the gain of the VOR response is enhanced (Jones et al., 1984). However, the effects of higher-order visual stimuli such as bistable perception or attention tasks requiring visualized spatial manipulation are unknown.

Bistable perception implies higher-order visual phenomena in which salient stimuli spontaneously disappear from visual aware-

\footnotetext{
Received April 26, 2012; revised Dec. 16, 2012; accepted Dec. 20, 2012.

Author contributions: Q.A., Y.N., and A.M.B. designed research; Q.A. and Y.N. performed research; A.M.B. contributed unpublished reagents/analytic tools; Y.N. analyzed data; Q.A., Y.N., and A.M.B. wrote the paper.

This work was supported by the Medical Research Council of the U.K. We thank David Buckwell for his technical assistance, Dr. Saiful Islam for statistical advice, Dr. Parashkev Nachev and Professor Michael Gresty for scientific discussion, and Dr. David Soto for his most helpful critique.

${ }^{*} Q$.A. and Y.N. made equal contributions to this work.

Correspondence should be addressed to Professor Adolfo M Bronstein, Academic Department of Neuro-Otology, Imperial College London, Charing Cross Hospital Campus, Fulham Palace Road, London, W6 8RF, UK. E-mail: a.bronstein@imperial.ac.uk.

DOI:10.1523/JNEUROSCI.2054-12.2013

Copyright $\odot 2013$ the authors $\quad 0270-6474 / 13 / 333221-07 \$ 15.00 / 0$
}

ness. Such perceptual phenomena include binocular rivalry and motion-induced blindness (MIB) (Bonneh et al., 2001; Knapen et al., 2011). The processing of such stimuli involves frontoparietal areas that have additionally been implicated in processing complex cognitive attentional tasks (that require visual imagery) and vestibular signals (Corbetta et al., 1998; Lumer et al., 1998; Bonneh et al., 2001; Corbetta and Shulman, 2002; Dieterich et al., 2003; Kanai et al., 2011). Lesions in these cortical areas cause spatial neglect by disrupting visuospatial attention, alter (bistable) perceptual transition dynamics, and induce VOR asymmetry (Ventre-Dominey et al., 2003; Bonneh et al., 2004). Reciprocally, vestibular activation can alter perceptual dynamics of bistable perception by modulating perceptual predominance of the rivaling images (Miller et al., 2000) and temporarily alleviate hemispatial neglect (Rubens, 1985).

Thus, it appears that processing of vestibular signals, visuospatial attention, and bistable perception are intertwined. As this has not yet been directly investigated, here we attempt to modulate the VOR by exposing subjects to visuospatial attention tasks and perceptual transitions such as binocular rivalry.

\section{Materials and Methods}

The experimental strategy consisted of assessing the effects of viewing bistable perceptual visual stimuli or performing visuospatial attention tasks during velocity step rotations upon the post-rotational VOR (stopping) responses.

\section{Experimental apparatus}

A motorized rotating chair (Contraves) was used to deliver constant velocity rotations in yaw $\left(90^{\circ} / \mathrm{s}\right)$. The chair was surrounded by a $1.44-\mathrm{m}-$ diameter black and white striped $\left(0.1\right.$ cycles $\left./^{\circ}\right)$ drum (Fig. 1a). 
a

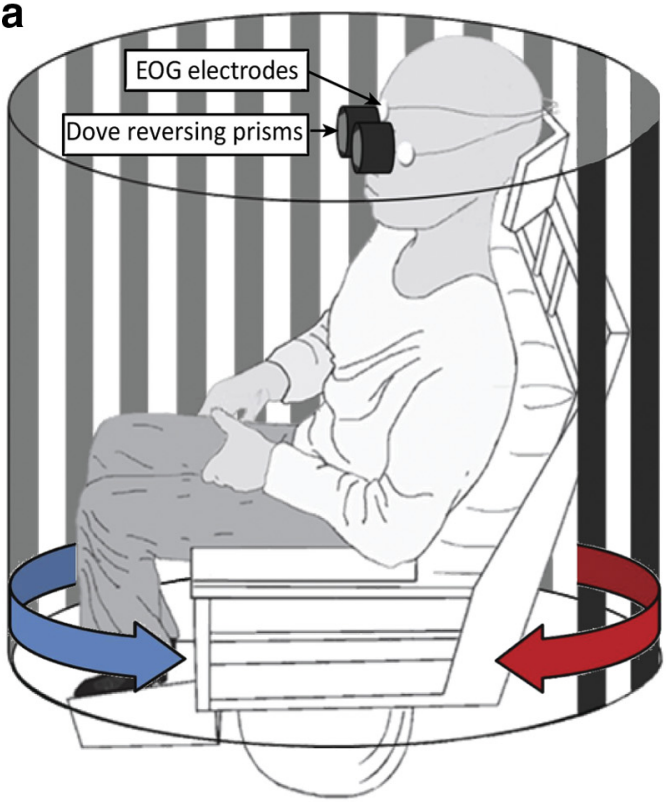

b

Non-rivalrous control

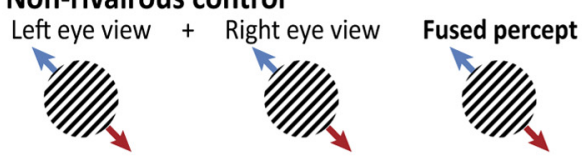

Motion rivalry

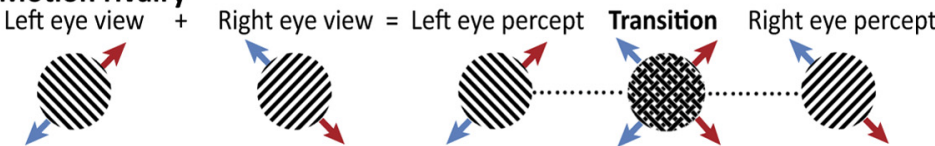

Colour rivalry

Left eye view + Right eye view $=$ Left eve percept Transition Right eye percept
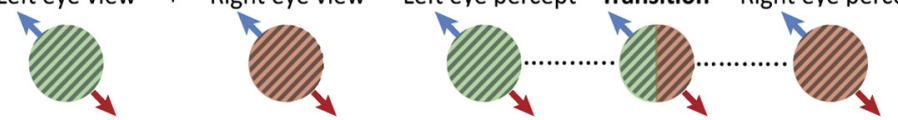

Motion and Colour rivalry

Left eye view + Right eye view $=$ Left eye percept Transition Right eye percept
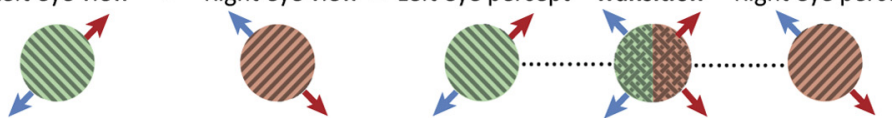

C

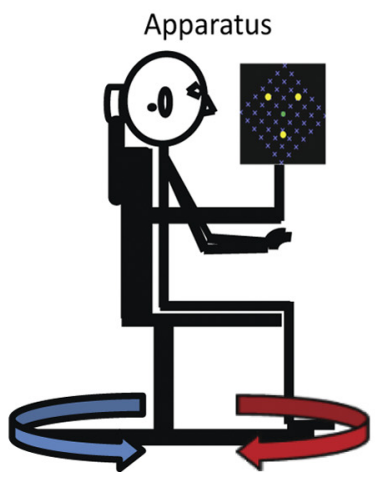

MIB condition

Binocular view

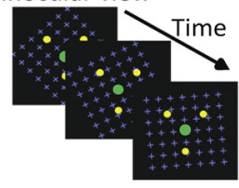

Control condition

Binocular view

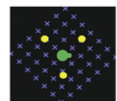

Examples of of possible percepts

$=$

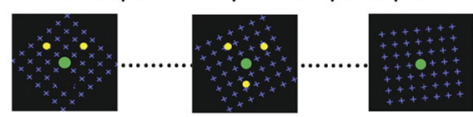

Single percept

$=$

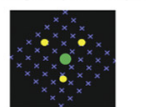

Figure 1. Bistable stimuli experimental setup. $\boldsymbol{a}$, Subjects were seated on a motorized chair rotating rightwards (red arrow) or leftwards (blue arrow) while viewing the striped drum through a pair of Dove reversing prisms. $\boldsymbol{b}$, Direction of grating motion seen in each eye during rightward (red arrows) and leftward rotations (blue arrows). Four conditions were created: non-rival rous control stimulus (identically oriented $+45^{\circ}$ gratings to both eyes), motion rivalry stimulus (orthogonally oriented gratings of $+45^{\circ}$ and $-45^{\circ}$ to the right and left eye respectively), color rivalry stimulus $\left(+45^{\circ}\right.$ gratings to both eyes; green and red color filters applied to the left and right eye, respectively) and color and motion rivalry stimulus. During rivalry, periods of mixed dominance occurred during transitions. c, MIB stimulus (or static control) was presented to subjects on a screen monitor. While fixating the central dot, subjects experience disappearance/reappearance of yellow dots when overlaid by a pattern of clockwise-moving blue dots. A static background in the control condition resulted in a single percept.

Bistable perceptual visual stimuli

Binocular rivalry condition. Subjects seated on the motorized chair viewed the drum through a pair of Dove reversing prisms (Fig. 1a,b). Following $20 \mathrm{~s}$ rotation (leftward or rightward), the chair was stopped in the dark and the VOR was measured (Fig. 2a). Viewing the striped background through the prisms while rotating can induce differential grating motion in the two eyes and competition for the dominant percept. By altering the orientation of the prisms in the two eyes and/or application of color filters, 3 different rivalrous stimuli ("motion rivalry," "color rivalry," and "motion and color rivalry") were created (Fig. 1b). A control non-rivalrous condition was implemented consisting of prisms presented in the same orientation $\left(+45^{\circ}\right)$ to both eyes to ensure a single fused percept (Fig. 1b).

Motion-induced blindness condition. A screen monitor was fixed to the chair at a distance of $40 \mathrm{~cm}$ from the subjects' eyes (Fig. 1c). The MIB stimulus consisted of three yellow dots $\left(0.2^{\circ}\right)$ and a green fixation dot arranged along a $1^{\circ}$ radius circle forming a triangle, overlaid on a global clockwise-moving pattern of blue dots on a black background (Bonneh et al., 2001). The subjects experienced disappearance and reappearance of yellow dots as they fixated the central green dot during the $20 \mathrm{~s}$ (leftward or rightward) rotations (Bonneh et al., 2001). The chair was stopped as the screen went black and the VOR was recorded (Fig. 2b). A control condition with a stationary background resulted in a single percept (this task also serves as a control for any VOR suppression-related effects).

\section{Attentional tasks}

Visuospatial attention task. Subjects performed a modified version of the Brooks visuospatial working memory task (Brooks, 1967) whereby 6 single-digit numbers were randomly allocated to 6 specified locations in a visually imagined $3 \times 3$ grid. A new digit was added to the imagined grid every $2.5 \mathrm{~s}$. This task was performed as the subjects rotated in the dark for $20 \mathrm{~s}$ before the chair halt (Fig. $2 c$ ). Performance was assessed by asking subjects to fill the grid with the remembered numbers after each rotation. Any trial where subjects failed to remember at least 4 numbers in correct grid locations was repeated, to ensure that sufficient attentional load was provided (Lavie, 2005). In addition, we altered the attentional load (Lavie, 2005) by giving subjects 3 numbers to remember in the grid. In this low-load task, the subjects were always able to recall all the numbers and their locations.

Non-visuospatial attention task. Subjects performed a modified nonvisuospatial digit span memory task (Wechsler, 2008), which involved subjects repeating and memorizing a string of single-digit numbers with a new digit added to the string every $2.5 \mathrm{~s}$. This task was performed as the subjects rotated in the dark for $20 \mathrm{~s}$ and the VOR was measured after the 
a Trial 1 Trial 2

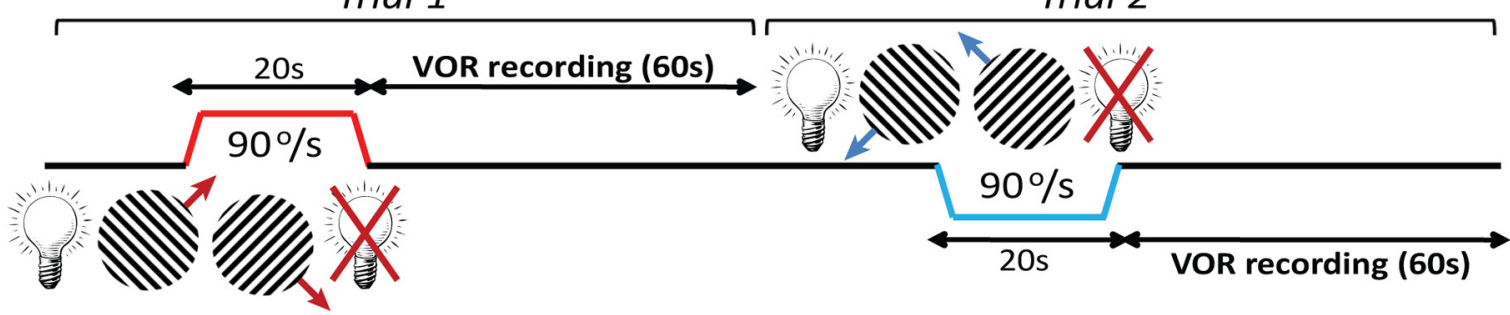

b

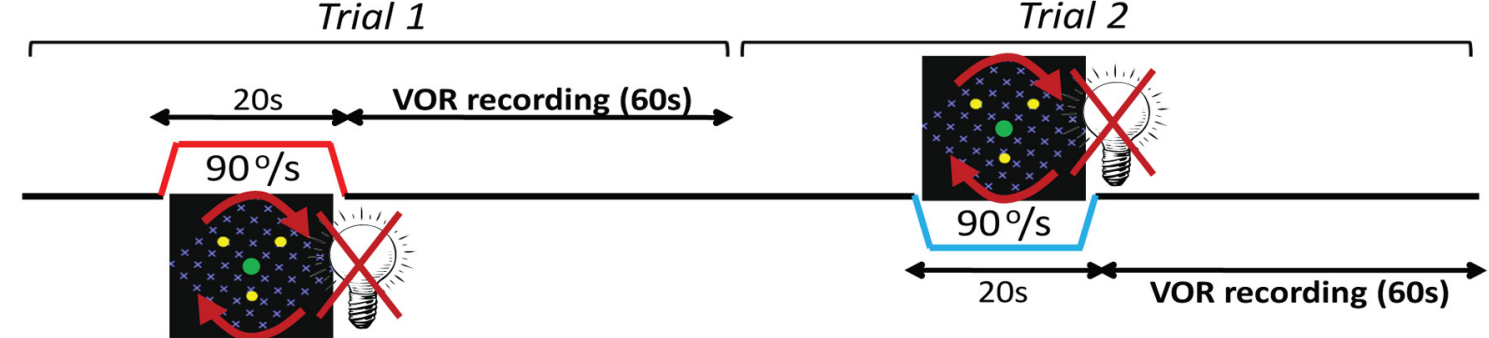

C

Trial 1

Trial 2

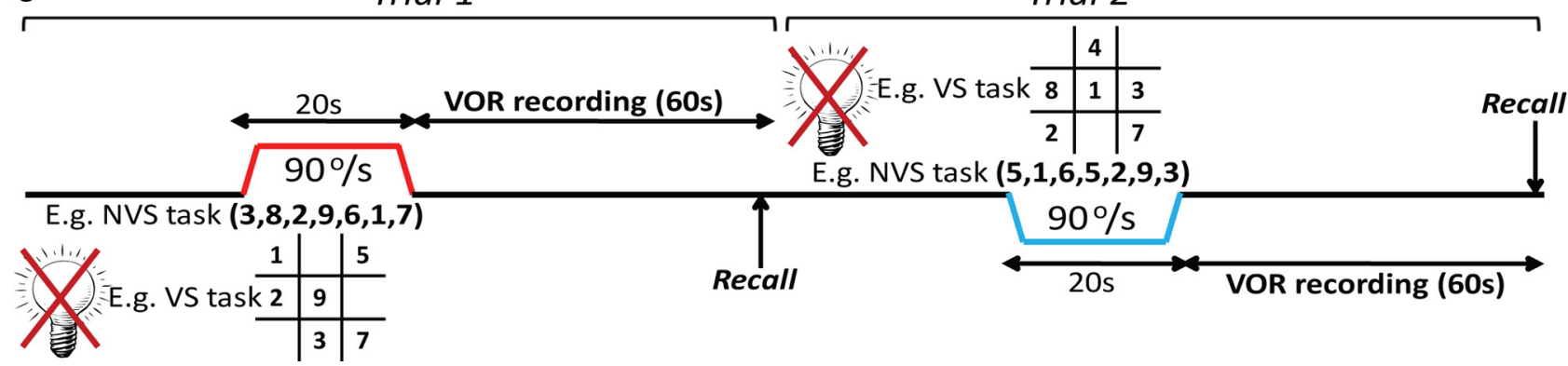

Figure 2. Protocol for bistable stimuli and attentional tasks. $\boldsymbol{a}-\boldsymbol{c}$, Two trials of $20 \mathrm{~s} 90^{\circ} / \mathrm{s}$ step rotations are shown for Rivalrous motion stimulus $(\boldsymbol{a})$, MIB stimulus(b), and Attentional, non-visuospatial (NVS) and visuospatial (VS) (c) tasks. Leftward rotation indicated in blue and rightward rotation in red. VOR always recorded after the chair halt in the dark.

chair halt (Fig. 2c). Subjects' performance was assessed by asking the subject to verbally recall the numbers at the end of each trial, a string of 7 numbers for the high-load condition and 4 numbers in the low-load condition. Any trial in the high-load condition in which subjects failed to recall at least 5 numbers was repeated. A higher criterion was set in the non-visuospatial task since pilot studies and literature indicated that this purely verbal recall task is comparatively easier than the visuospatial task (Kessels et al., 2008).

\section{Experimental protocol}

For the binocular rivalry and MIB conditions, each trial began in the light with the chair rapidly accelerating $(0.5 \mathrm{~s})$ to a constant velocity of $90 \%$, while the trials with the attentional tasks were always performed in darkness. After $20 \mathrm{~s}$ of chair rotation (rightward or leftward) either in the light (rivalry and MIB conditions) or dark (attentional tasks), the chair was always stopped in the dark (Fig. 2). For each task, 2 trials were performed in a randomized order in each direction. Eye movements were recorded using horizontal binocular DC-EOG.

The duration of the rotational stimulus was reduced to $20 \mathrm{~s}$ in our experiments to allow for maximal concurrent visual and vestibular activation, and to avoid exceeding the subjects' limits for attention span.

\section{Subjects}

Subjects (age range $21-65$ years, mean $=30.7$ years) were healthy, naïve, and had normal corrected vision and normal binocular and color vision. One set of subjects completed all binocular rivalry experiments, a separate set the MIB study, and a further separate set the attention tasks. Only 16 out of a total of 90 subjects [ 39 female (F)/51 male (M)] participated in more than one set of experiments, but since these 16 subjects were tested 6 months apart and there was no potential of carryover effects, repeated- measures statistics were not used. Ten right-handed subjects were recruited for the rivalry conditions $(6 \mathrm{M} / 4 \mathrm{~F}), 10$ right-handed subjects for the motion-induced blindness $(4 \mathrm{M} / 6 \mathrm{~F}), 10$ right-handed subjects for the supplemental MIB condition (4M/6F), 10 right-handed subjects for the visuospatial attention task $(6 \mathrm{M} / 4 \mathrm{~F})$, and 10 right-handed subjects $(5 \mathrm{M} /$ $5 \mathrm{~F})$ for the non-visuospatial attention task. In the handedness experiments, for the motion rivalry condition, 12 right-handed $(7 \mathrm{M} / 5 \mathrm{~F})$ and 8 left-handed $(7 \mathrm{M} / 1 \mathrm{~F})$ subjects were recruited; for the visuospatial task, 12 right-handed $(6 \mathrm{M} / 6 \mathrm{~F})$ and 8 left-handed subjects were recruited $(6 \mathrm{M} / 2 \mathrm{~F})$.

Participants completed an Edinburgh handedness inventory questionnaire (Oldfield, 1971); all had a handedness score $>40$ (considered as right-handed) or $<-40$ (considered left-handed). Subjects successfully confirmed the presence of perceptual transitions during bistable perceptual stimuli. The switching rate for perceptual transitions was not measured, as a mosaic (mixed percept) is reported predominantly in the motion rivalry condition (Andrews and Blakemore, 2002). Of note, there is no difference in the duration of perceiving rightward versus leftward motion during binocular rivalry (Hayashi and Tanifuji, 2012).

\section{Data analysis}

Binocular EOG and chair motion signals were saved on a computer sampling at $250 \mathrm{~Hz}$. Calibrated EOG signals were differentiated and desaccaded to obtain eye velocity curves, which were averaged separately for right and left stopping responses. Averaged eye velocity curves were fitted with an exponential function to determine the main time constant (TC) of decay of the VOR ( $\mathrm{VOR}_{\mathrm{TC}}$ ) (Okada et al., 1999). $\left[\mathrm{VOR}_{\mathrm{TC}}\right.$ in humans is $\sim 16 \mathrm{~s}$ as a result of the velocity storage mechanism in the 


\section{a Rivalrous stimuli}

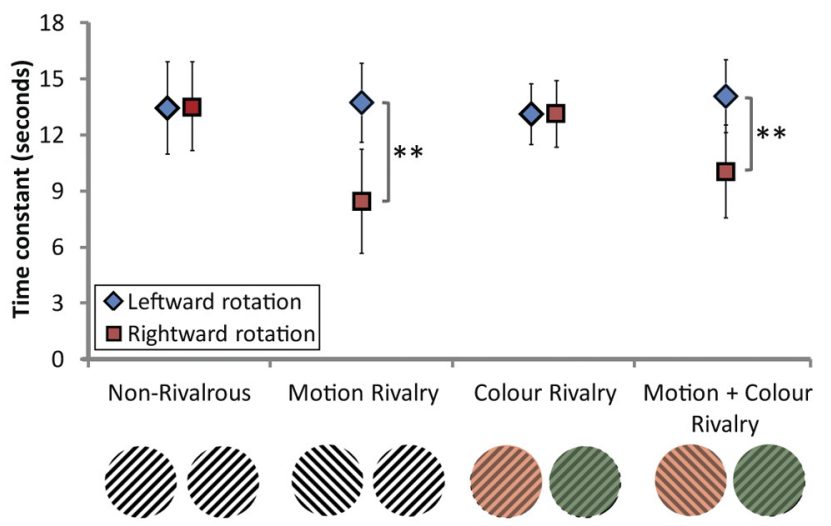

\section{Visuospatial attention task}

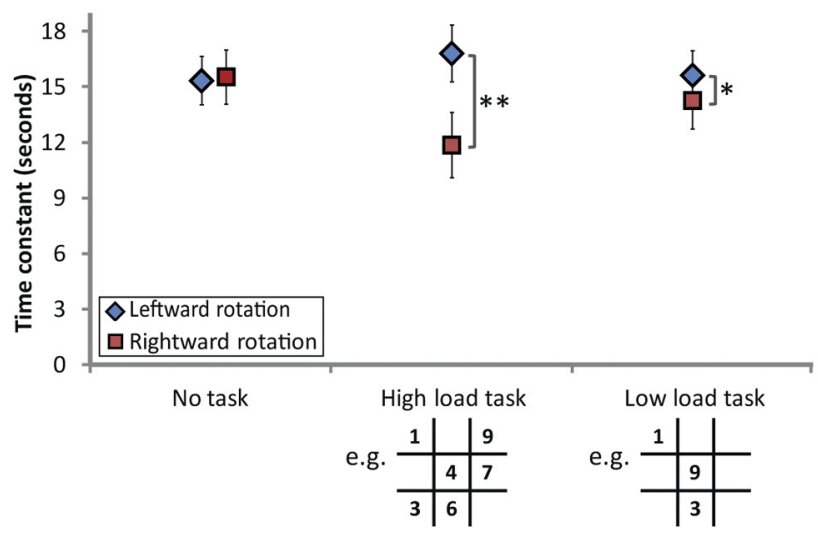

\section{b $\underline{\text { MIB }}$}

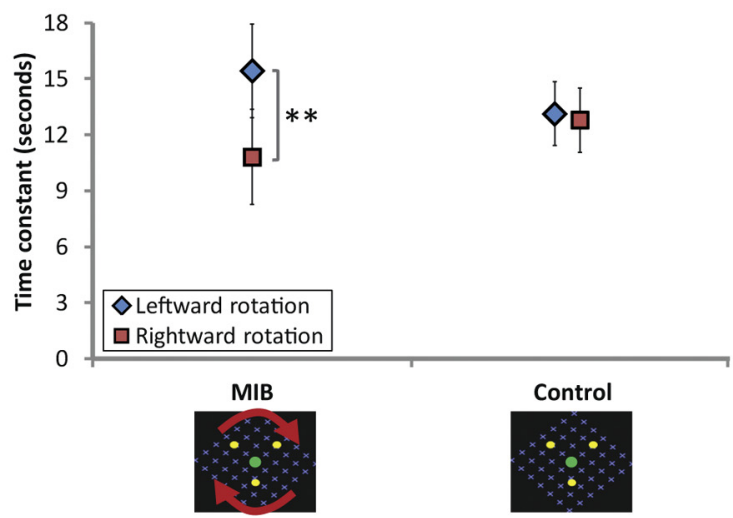

d Non visuospatial attention task

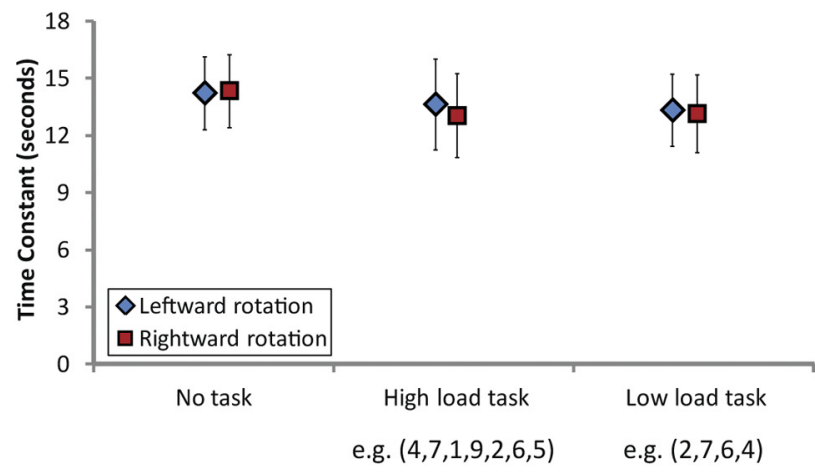

Figure 3. Effect of bistable stimuli and attentional tasks on $\mathrm{VOR}_{\mathrm{TC}}$ in different sets of 10 right-handed individuals. $\boldsymbol{a}, \boldsymbol{b}$, The bistable stimuli that contain spatial component (motion rivalry, motion-and-color rivalry, and MIB) produced asymmetric VOR modulation by reducing TC following the rightward (red squares) compared with leftward rotations (blue diamonds). $\boldsymbol{c}, \boldsymbol{d}$, High- and low-load visuospatial attention tasks induced asymmetric VOR responses but non-visuospatial digit tasks demonstrated no modulation. Bars represent SD; ${ }^{*} p<0.01 ;{ }^{* *} p<0.001$.

brainstem, which prolongs the vestibular nerve signal (Raphan et al., 1979)].

To quantify VOR asymmetry, we calculated the $\mathrm{VOR}_{\mathrm{TC}}$ Asymmetry Index (or directional preponderance):

$\mathrm{VOR}_{\mathrm{TC}}$ Asymmetry Index (\%)

$$
=\frac{(\text { Left stop TC }- \text { Right stop TC })}{(\text { Left stop TC }+ \text { Right stop TC })} \times 100
$$

(Positive Asymmetry Index denotes shortened VOR response following rightward rotation while negative Asymmetry Index represents shortened VOR following leftward rotation.)

\section{Results}

\section{Effect of perceptual transitions on VOR}

Binocular rivalry condition

Motion rivalry in the 10 right-handed subjects caused asymmetric VOR responses in the dark. $\mathrm{VOR}_{\mathrm{TC}}$ of the right stopping responses were significantly reduced compared with $\mathrm{VOR}_{\mathrm{TC}}$ following leftward rotations ( $p<0.001$, paired $t$ test; Fig. $3 a$ ) with a mean positive $\mathrm{VOR}_{\mathrm{TC}}$ Asymmetry Index of $25.4 \%$. The color rivalry condition showed similar results to the control nonrivalrous condition producing symmetric VOR responses $(p>$ 0.05 , paired $t$ tests; Fig. $3 a$ ). However, when the motion rivalry was added to the color rivalry (motion and color rivalry condition), VOR responses were reduced after rightward rotations as in motion rivalry $\left(\mathrm{VOR}_{\mathrm{TC}}\right.$ Asymmetry Index $\left.=+17.6 \%\right)$. The presence of motion rivalry was the defining factor in producing asymmetric VOR responses $(p<0.001, f=78.1, \mathrm{df}=1$, Direction $\times$ Condition interaction, repeated-measures ANOVA; Fig. $3 a$ ).

We performed a control condition to demonstrate that the asymmetrical modulation of the VOR was not attributable to the incongruence between the plane of visual (oblique plane) and head motion (horizontal plane). Thus, we induced horizontal motion rivalry by applying a reversing prism set at $0^{\circ}$ in one eye, while the other eye viewed motion unobstructed. Both oblique and horizontal rivalry modulated the VOR in an identical manner (data not shown). We also performed a control experiment during motion rivalry to minimize eye tracking movements whereby a central fixation cross was presented to both eyes. Subjects were required to fuse the two crosses to stabilize gaze (Alais and Blake, 1999). We observed an identical modulation of the VOR (data not shown). Finally, a control experiment was run using motion rivalry to demonstrate that these asymmetries are still significant when using conventional rotational stimuli of $60 \mathrm{~s}$ duration (data not shown).

Motion-induced blindness condition

All 10 right-handed participants demonstrated reduced TC $(p<$ 0.001 , paired $t$ test) following rightward rotations with a mean positive $\mathrm{VOR}_{\mathrm{TC}}$ Asymmetry Index of $17.9 \%$. In the control condition the VOR responses were symmetric $(p>0.05$, paired $t$ test; Fig. $3 b$ ).

To ensure the direction of background motion was not important, a supplemental stimulus was used in 10 right-handed 


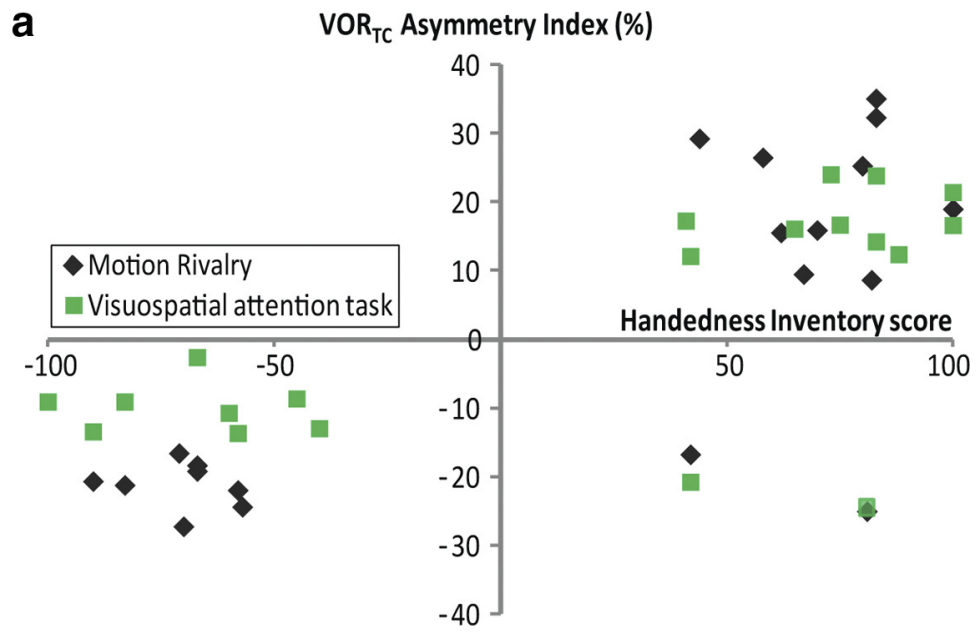

b Non-Rivalrous condition
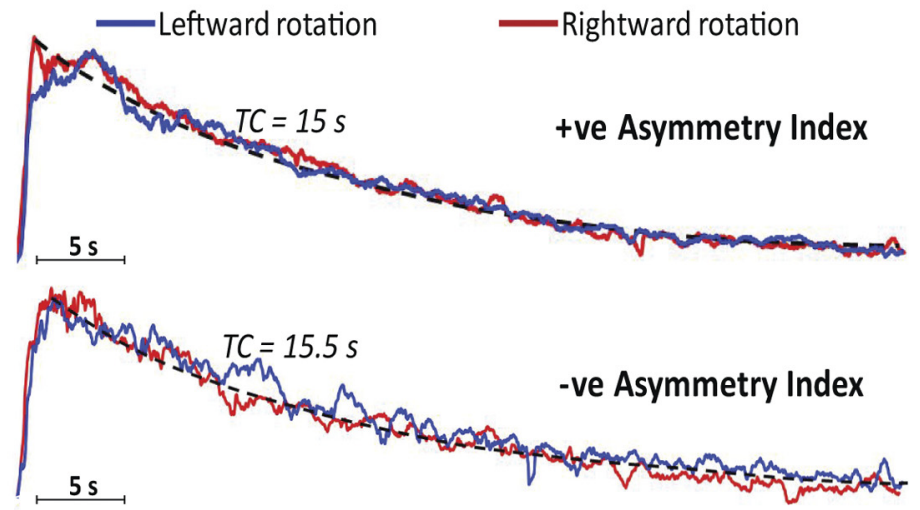

C Motion Rivalry condition
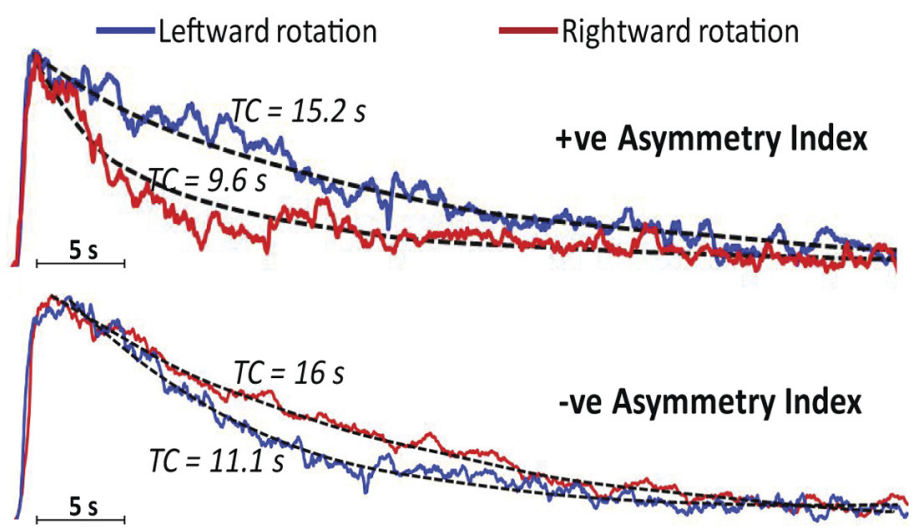

Figure 4. Result summary for the handedness experiments. $\boldsymbol{a}$, Plots each subject's individual asymmetry index and handedness inventory score. Different sets of right handers showed a positive VOR $\mathrm{R}_{\mathrm{TC}}$ Asymmetry Index for the motion rivalry condition (black diamonds) and visuospatial task (green squares) whereas all left-handed subjects and 2 right-handed subjects had a negative $\mathrm{VOR}_{\mathrm{TC}}$ Asymmetry Index. $\boldsymbol{b}, \boldsymbol{c}$, Grand averages of eye velocity recordings (in arbitrary units for illustration purposes) for individuals with positive and negative $\mathrm{VOR}_{\mathrm{TC}}$ Asymmetry Index in non-rivalrous condition (b) and motion rivalry condition (c).

participants which consisted of three yellow dots $\left(0.2^{\circ}\right)$ arranged on a dynamic blue random dot pattern (Bonneh et al., 2001). Asymmetrical VOR responses were observed with reduced TC following rightward rotations $\left(p<0.001\right.$, paired $t$ test; $\mathrm{VOR}_{\mathrm{TC}}$ Asymmetry index $=+16.4 \%)$.

Our results showed that MIB and rivalrous stimuli with a spatial component (motion rivalry and motion and color rivalry) asymmetrically modulate the VOR by shortening VOR responses on rightward stoppings (Fig. 3a,b).

Effect of attentional tasks on the VOR Visuospatial attention task

The control condition, in which subjects received no task while rotating in the dark for $20 \mathrm{~s}$, showed symmetric VOR responses ( $p>0.05$, paired $t$ test; Fig. $3 c$ ). Both high- and low-load visuospatial attention tasks induced asymmetric $\mathrm{VOR}_{\mathrm{TC}}$ following rightward rotations with mean $\mathrm{VOR}_{\mathrm{TC}}$ Asymmetry Index of $+17.5 \%$ and $+4.6 \%$, respectively $(p<0.001, f=126.7$, $\mathrm{df}=1$, Direction, repeated-measures ANOVA). The asymmetries induced by the low-load attention compared with high load were significantly smaller $(p<$ $0.001, f=247.4, \mathrm{df}=1$, Load $\times$ Direction interaction; Fig. $3 c$ ). Inspection of the EOG traces did not detect voluntary or "scanning" eye movements during the attentional tasks; responses were dominated by robust vestibular nystagmus.

Non-visuospatial attention task As expected, the control condition with no task showed symmetric VOR responses and neither high- nor low-load digit span task asymmetrically modulated the VOR $(p>$ $0.05, f=3.3, \mathrm{df}=1$, Direction) with data not differing from the control condition $(p>0.05, f=2.5$, df $=2$, repeatedmeasures ANOVA; Fig. 3d).

Thus, the presence of a visuospatial component in the attentional task is critical for the asymmetric modulation of the VOR; hence attention per se is not responsible.

\section{Lateralization of VOR modulation} according to subjects' handedness The above results show that both perceptual transitions and attentional tasks entailing a spatial component modulate the oculomotor response by reducing the $\mathrm{VOR}_{\mathrm{TC}}$ of decay following rightward rotations compared with leftward rotations in right-handed individuals. We performed a further study using binocular motion rivalry and visuospatial attention stimuli to investigate the effect in left-handed individuals.

Subjects participated in a motion rivalry experiment with the same experimental set up (Fig. 1a). Two conditions were performed: motion rivalry and a control nonrivalrous condition described above (Figs. $1 b, 2 a)$. As expected the non-rivalrous control condition produced symmetric VOR responses ( $p>0.05$, paired $t$ test; Fig. $4 b$ ). In the rivalrous condition, the VOR was asymmetrically modulated with TCs reduced following the rightward rotations in 10 of 12 righthanded individuals $(p<0.001$, paired $t$ test; Fig. $4 a$ ) with a mean $\mathrm{VOR}_{\mathrm{TC}}$ Asymmetry Index of $+21.7 \%$ (Fig. $4 c$ ). The $\mathrm{VOR}_{\mathrm{TC}}$ Asym- 
metry Index was negative in all 8 left- and 2 right-handed participants with a mean asymmetry index of $-21.2 \%$, i.e., the VOR was shortened following the leftward rotations $(p<0.001$, paired $t$ test; Fig. 4a,c).

In the high-load visuospatial task condition, the VOR was asymmetrically modulated with TCs reduced following the rightward rotations in 10 of 12 right-handed individuals $(p<0.001$, paired $t$ test; Fig. $4 a$ ). The $\mathrm{VOR}_{\mathrm{TC}}$ Asymmetry Index was negative in all 8 left and the same 2 right-handed participants with a mean asymmetry index of $-13.5 \%$ ( $p<0.001$, paired $t$ test; Fig. $4 a)$.

Grouping all participants in the lateralization experiments, laterality with handedness was found in 32 of 34 (94.1\%) of subjects. On further questioning, the two right handers with the negative asymmetry index had a family history of left-handedness.

In all conditions (bistable perception and attentional tasks) there was no effect on the gain of the VOR ( $p$-values ranging between 0.064 and 0.78 ; paired $t$ tests).

\section{Discussion}

The VOR is not a rigid reflex as it can be altered bidirectionally by visual input, mental imagery (Barr et al., 1976) and habituation to repeated rotations (Cohen et al., 1992) that impact upon the central velocity storage mechanism.

Perceptual transitions (binocular rivalry and MIB) and spatial attention tasks asymmetrically modulated VOR responses. The modulation observed was dependent upon the subject's handedness. VOR time constants approached vestibular nerve values, implying downregulation of the central velocity mechanism (Raphan et al., 1979), following rightward rotation in right handers and leftward rotations in left handers. Since both visuospatial attention and perceptual transitions (with a spatial component) modulated the VOR in a similar manner it rules out the possibility that pursuit eye movements or visual motion caused this downregulation. Moreover, it is known that both phenomena, as well as handedness, are cortically based (Leopold and Logothetis, 1996; Corbetta and Shulman, 2002; Dieterich et al., 2003; Sterzer and Kleinschmidt, 2007), hence the observed asymmetric modulation of the VOR is likely to be mediated by higher-order mechanisms.

During concurrent visuospatial and vestibular activation, the brain networks involved overlap considerably. Spatial mental imagery and perceptual transitions generate activity in overlapping parietal areas (Brotchie et al., 1995; Corbetta and Shulman, 2002; Kanai et al., 2011) to those that mediate prolongation of VOR responses in the non-dominant hemisphere (Ventre-Dominey et al., 2003). Also, voluntary non-visual modulation of the VOR requires visuospatial mental imagery (Barr et al., 1976) and such ability is particularly reduced in parietal cortical lesions (Sharpe and Lo, 1981).

Hence, regardless of the stimuli used, the lateralized frontoparietal attentional network is activated, in accord with the view that visuospatial attention and bistable perception call upon a common neural mechanism (Lumer et al., 1998; Knapen et al., 2011). Resolving bistable perception or performing visuospatial attention tasks during vestibular activation may result in functional overloading of the non-dominant hemisphere with utilization of common processing resources (Corbetta et al., 1998; Lumer et al., 1998; Dieterich et al., 2003), leading to disruption of parietal interhemispheric balance (Sparing et al., 2009).

Disruption of interhemispheric balance by the attentional demand placed upon the non-dominant parietal lobe renders it less able to contribute to vestibular nystagmus prolongation as it continues to coprocess the bistable perceptual tasks. Notably, such disruption of parietal interhemispheric balance persists during the stopping response (despite the absence of any physical visual stimulus) as activity in the frontoparietal regions continues for $\sim 10$ s, a phenomenon termed "perceptual memory" (Sterzer and Rees, 2008). The end result, reduced left beating nystagmus in right handers and right beating nystagmus in left handers, may be mediated by ipsilateral parietal descending projections to the vestibular nuclei (Ventre and Faugier-Grimaud, 1986). It would then follow, that by reducing the attentional load (Lavie, 2005) as in the visuospatial attention task, more resources in the nondominant hemisphere can be allocated to vestibular processing and, hence, the asymmetries in the VOR responses should be reduced. Indeed, we have shown this to be the case.

Our results provide novel evidence that bistable perceptual stimuli with a spatial component (e.g., binocular motion rivalry but not color rivalry; Carney et al., 1987) are able to modulate the function of a separate sensory-motor system, the VOR. Furthermore, they demonstrate that the VOR is subject to handednessrelated cortical modulation and suggest that velocity storage and visuospatial processing draw upon common cortical processing resources, strongly lateralized to the non-dominant hemisphere (94\%). Previous suggestions of lateralization of vestibular cortical processing were based on functional imagining (Dieterich et al., 2003) or lesion studies (Ventre-Dominey et al., 2003). The latter study reported suppressed TCs in the direction of the (lesioned) non-dominant hemisphere but normal VOR gain. Therefore, parietal disruption either via a lesion (VentreDominey et al., 2003) or functional overloading (this study) can downregulate the velocity storage integrator without affecting VOR gain.

Research has shown vestibular influences upon spatial attention, e.g., alleviating neglect symptoms after right parietal lesions (Rubens, 1985) and caloric stimulation altering perpetual transitions in binocular rivalry (Miller et al., 2000). Here we demonstrate the converse interaction in which spatial attention exhibits a strong influence on vestibular function. As both networks are considerably lateralized to the non-dominant hemisphere, the handedness-related VOR asymmetry induced may reflect the presence of spatial occlusion between convergent vestibular and spatial attention cortical circuits. Thus, current and previous findings together indicate a bidirectional modulation between vestibular and spatial attentional mechanisms, which may contribute to the control of spatial orientation.

\section{References}

Alais D, Blake R (1999) Grouping visual features during binocular rivalry. Vision Res 39:4341-4353. CrossRef Medline

Andrews TJ, Blakemore C (2002) Integration of motion information during binocular rivalry. Vision Res 42:301-309. CrossRef Medline

Barr CC, Schultheis LW, Robinson DA (1976) Voluntary, non-visual control of the human vestibulo-ocular reflex. Acta Otolaryngol 81:365-375. CrossRef Medline

Bonneh YS, Cooperman A, Sagi D (2001) Motion-induced blindness in normal observers. Nature 411:798-801. CrossRef Medline

Bonneh YS, Pavlovskaya M, Ring H, Soroker N (2004) Abnormal binocular rivalry in unilateral neglect: Evidence for a non-spatial mechanism of extinction. Neuroreport 15:473-477. CrossRef Medline

Brooks LR (1967) The suppression of visualization by reading. Q J Exp Psychol 19:289-299. CrossRef Medline

Brotchie PR, Andersen RA, Snyder LH, Goodman SJ (1995) Head position signals used by parietal neurons to encode locations of visual stimuli. Nature 375:232-235. CrossRef Medline

Carney T, Shadlen M, Switkes E (1987) Parallel processing of motion and colour information. Nature 328:647-649. CrossRef Medline

Cohen H, Cohen B, Raphan T, Waespe W (1992) Habituation and adaptation of the vestibuloocular reflex: a model of differential control by the vestibulocerebellum. Exp Brain Res 90:526-538. Medline 
Corbetta M, Shulman GL (2002) Control of goal-directed and stimulusdriven attention in the brain. Nat Rev Neurosci 3:201-215. Medline

Corbetta M, Akbudak E, Conturo TE, Snyder AZ, Ollinger JM, Drury HA, Linenweber MR, Petersen SE, Raichle ME, Van Essen DC, Shulman GL (1998) A common network of functional areas for attention and eye movements. Neuron 21:761-773. CrossRef Medline

Dieterich M, Bense S, Lutz S, Drzezga A, Stephan T, Bartenstein P, Brandt T (2003) Dominance for vestibular cortical function in the non-dominant hemisphere. Cereb Cortex 13:994-1007. CrossRef Medline

Hayashi R, Tanifuji M (2012) Which image is in awareness during binocular rivalry? Reading perceptual status from eye movements. J Vis 12(3):5 $1-11$. CrossRef

Jones GM, Berthoz A, Segal B (1984) Adaptive modification of the vestibulo-ocular reflex by mental effort in darkness. Exp Brain Res 56: 149-153. Medline

Kanai R, Carmel D, Bahrami B, Rees G (2011) Structural and functional fractionation of right superior parietal cortex in bistable perception. Curr Biol 21:R106-R107. CrossRef Medline

Kessels RP, van den Berg E, Ruis C, Brands AM (2008) The backward span of the Corsi Block-Tapping Task and its association with the WAIS-III Digit Span. Assessment 15:426-434. CrossRef Medline

Knapen T, Brascamp J, Pearson J, van Ee R, Blake R (2011) The role of frontal and parietal brain areas in bistable perception. J Neurosci 31: 10293-10301. CrossRef Medline

Lavie N (2005) Distracted and confused? Selective attention under load. Trends Cogn Sci 9:75-82. CrossRef Medline

Leopold DA, Logothetis NK (1996) Activity changes in early visual cortex reflect monkeys' percepts during binocular rivalry. Nature 379:549-553. CrossRef Medline

Lumer ED, Friston KJ, Rees G (1998) Neural correlates of perceptual rivalry in the human brain. Science 280:1930-1934. CrossRef Medline

Miller SM, Liu GB, Ngo TT, Hooper G, Riek S, Carson RG, Pettigrew JD
(2000) Interhemispheric switching mediates perceptual rivalry. Curr Biol 10:383-392. CrossRef Medline

Okada T, Grunfeld E, Shallo-Hoffmann J, Bronstein AM (1999) Vestibular perception of angular velocity in normal subjects and in patients with congenital nystagmus. Brain 122:1293-1303. CrossRef Medline

Oldfield RC (1971) The assessment and analysis of handedness: the Edinburgh inventory. Neuropsychologia 9:97-113. CrossRef Medline

Raphan T, Matsuo V, Cohen B (1979) Velocity storage in the vestibuloocular reflex arc (VOR). Exp Brain Res 35:229-248. Medline

Rubens AB (1985) Caloric stimulation and unilateral visual neglect. Neurology 35:1019-1024. CrossRef Medline

Sharpe JA, Lo AW (1981) Voluntary and visual control of the vestibuloocular reflex after cerebral hemidecortication. Ann Neurol 10:164-172. CrossRef Medline

Sparing R, Thimm M, Hesse MD, Küst J, Karbe H, Fink GR (2009) Bidirectional alterations of interhemispheric parietal balance by non-invasive cortical stimulation. Brain 132:3011-3020. CrossRef Medline

Sterzer P, Kleinschmidt A (2007) A neural basis for inference in perceptual ambiguity. Proc Natl Acad Sci U S A 104:323-328. CrossRef Medline

Sterzer P, Rees G (2008) A neural basis for percept stabilization in binocular rivalry. J Cogn Neurosci 20:389-399. CrossRef Medline

Suzuki M, Kitano H, Ito R, Kitanishi T, Yazawa Y, Ogawa T, Shiino A, Kitajima K (2001) Cortical and subcortical vestibular response to caloric stimulation detected by functional magnetic resonance imaging. Brain Res Cogn Brain Res 12:441-449. CrossRef Medline

Ventre J, Faugier-Grimaud S (1986) Effects of posterior parietal lesions (area 7) on VOR in monkeys. Exp Brain Res 62:654-658. Medline

Ventre-Dominey J, Nighoghossian N, Denise P (2003) Evidence for interacting cortical control of vestibular function and spatial representation in man. Neuropsychologia 41:1884-1898. CrossRef Medline

Wechsler D (2008) Wechsler Adult Intelligence Scale-Fourth Edition (WAIS-IV). London: Pearson PLC. 